\title{
Effect of L-Ascorbic Acid on the Oxidative Modification of Apolipoprotein E in Human Very-Low-Density Lipoprotein
}

\author{
Hirofumi ARAI and Kazuyuki NAKAMURA* \\ Department of Biochemistry and Biomolecular Recognition, Yamaguchi University School of Medicine, \\ Ube 755-8505, Japan \\ (Received April 17, 2003)
}

\begin{abstract}
Summary Antioxidant activity of L-ascorbic acid (AsA) against oxidative modification of apolipoprotein (apo) E in human very-low-density lipoprotein (VLDL) was investigated. The VLDL oxidation induced by peroxyl radicals and peroxynitrite led to lipid peroxidation and oxidative modification of apoE. The binding activity of apoE to heparin was decreased by the oxidative modification. AsA (200, 500, and 1,000 $\mu \mathrm{M})$ inhibited both the lipid peroxidation and the oxidative modification of apoE. These results suggest that AsA prevents the biological function of apoE in VLDL from the oxidation by free radicals.
\end{abstract}

Key Words apolipoprotein E, L-ascorbic acid, oxidation, radicals, very-low-density lipoprotein

A number of studies have suggested that the oxidation of low-density lipoprotein (LDL) may contribute to the onset of atherosclerosis in humans (1-4). In the previous paper, Mohr and Stocker (5) have described the mechanism for lipid peroxidation of very-low-density lipoproteins (VLDL), a precursor of LDL. We have also referred to the mechanism of the oxidative modification of apolipoprotein (apo) E (6), which regulates VLDL metabolism by acting as the ligands for the LDL receptor and glycosaminoglycan along the LDL receptor-related protein pathway $(7,8)$.

$\mathrm{L}$-Ascorbic acid (AsA) is recognized to be a potential water-soluble antioxidant existing in human blood (9). In this paper, we study the effects of AsA on the lipid peroxidation and the oxidative modification of apoE in VLDL in vitro.

3-Morpholinosydnonimine (SIN-1), a peroxynitrite generator (10), was purchased from Dojindo Laboratories (Kumamoto, Japan). 2,2'-Azobis(2-amidinopropane) dihydrochloride (AAPH), a peroxyl radical generator, and AsA were obtained from Wako Pure Chemical Industries, Ltd. (Osaka, Japan). All other chemicals were of reagent grade. VLDL $(d<1.006 \mathrm{~g} / \mathrm{mL})$ was centrifugally separated from the fresh plasma withdrawn $12 \mathrm{~h}$ after fasting from a healthy volunteer with fully informed consent (11). VLDL (100 $\mu$ g protein) in TrisHCl-buffered saline (TBS; $\mathrm{pH} 7.4$ ) was oxidized by AAPH $(5 \mathrm{mM})$ or SIN-1 $(1 \mathrm{mM})$ at $37^{\circ} \mathrm{C}$ in the presence

\footnotetext{
* To whom correspondence should be addressed.

E-mail:nakamura@yamaguchi-u.ac.jp

Abbreviations: apo, apolipoprotein; AsA, L-ascorbic acid; AAPH, 2,2'-azobis (2-amidinopropane) dihydrochloride; CE$\mathrm{OOH}$, cholesteryl ester hydroperoxides; LDL, low-density lipoprotein; SDS-PAGE, sodium dodecyl sulfate-polyacrylamide gel electrophoresis; TBS, Tris-HCl-buffered saline; VLDL, verylow-density lipoprotein.
}

of AsA. Cholesteryl ester hydroperoxides (CE-OOH) were determined by UV measurement with a high-performance liquid chromatograph (HPLC; Hitachi, Japan) as described previously (12). ApoE in VLDL was subjected to sodium dodecyl sulfate-polyacrylamide gel electrophoresis (SDS-PAGE) in 10\% acrylamide slab gel (13), followed by Western blotting with goat anti-apoE antisera (Chemicon International, Temecula, CA, USA) as the primary antibody and peroxidase conjugated rabbit anti-goat IgG as the secondary antibody (14). For evaluation of the heparin binding activity of apoE, VLDL previously oxidized for $12 \mathrm{~h}$ was incubated with $25 \mathrm{mg}$ of heparin Sepharose CL-6B (Amersham Pharmacia Biotech Co., England) for $3 \mathrm{~h}$ at $4^{\circ} \mathrm{C}$, and then was washed 10 times with $1 \mathrm{~mL}$ of TBS containing $0.05 \%$ Tween 20. ApoE dissociable from heparin-Sepharose with an SDS-containing eluent was further subjected to SDS-PAGE and characterized by immunoblotting in the manner above-mentioned.

Figure 1 shows the effect of AsA on lipid peroxidation in VLDL. CE-OOH accumulated during VLDL oxidation by AAPH (A) or SIN-1 (B) in the absence of AsA. The concentration of AsA in human blood plasma has been reported to range from 30 to $150 \mu \mathrm{M}(9)$. In both oxidation systems, the accumulation of $\mathrm{CE}-\mathrm{OOH}$ was suppressed by AsA at a physiological concentration or more of 200, 500, and 1,000 $\mu \mathrm{M}$. Figure 2 shows the effect of AsA on the oxidative modification of apoE in VLDL. After the oxidation of VLDL for $12 \mathrm{~h}$ by AAPH (A) or SIN-1 (B) in the absence of AsA, apoE was detected as a smear band (lane 2), whereas intact apoE was detected at $34 \mathrm{kDa}$ (lane 1) by immunoblot analysis. The oxidative modification of apoE in VLDL by AAPH (A) or SIN-1 (B) was moderately avoided by the coexistence of AsA at concentrations of 200, 500, and 1,000 $\mu \mathrm{M}$ (lanes 3-5).

The binding sites of apoE to the LDL receptor or hep- 

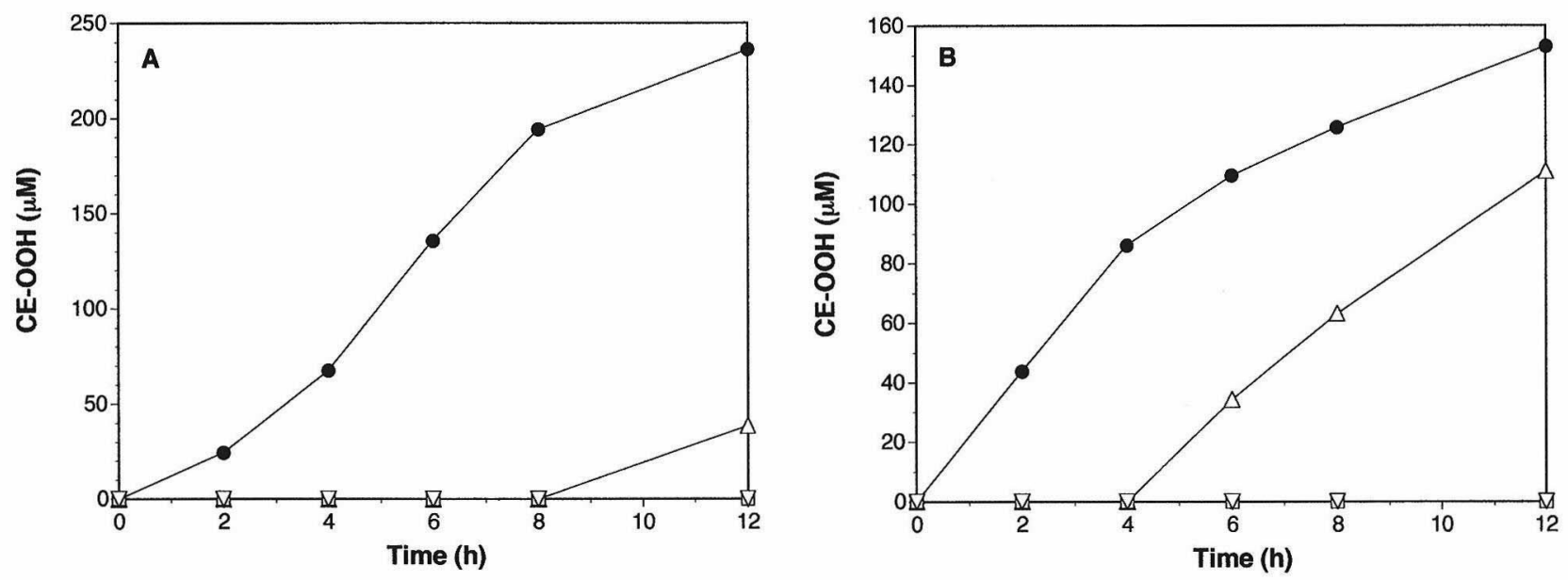

Fig. 1. Effect of L-ascorbic acid (AsA) on lipid peroxidation in human plasma very-low-density lipoprotein (VLDL). VLDL (100 $\mu \mathrm{g}$ of protein) was oxidized by $5 \mathrm{~mm} \mathrm{2,2'-azobis(2-amidinopropane)} \mathrm{dihydrochloride} \mathrm{(AAPH)} \mathrm{(A)} \mathrm{and} \mathrm{by} 1 \mathrm{mM} 3-$ morpholinosydnonimide (SIN-1) (B) in $500 \mu \mathrm{L}$ of Tris-HCl-buffered saline ( $\mathrm{pH} 7.4$ ) at $37^{\circ} \mathrm{C}$. AsA was added to VLDL before the oxidation. Cholesteryl ester hydroperoxides were determined by reversed-phase high-performance liquid chromatography. The concentration of AsA was as follows: none $(\bullet), 200 \mu \mathrm{M}(\triangle), 500 \mu \mathrm{M}(\square), 1,000 \mu \mathrm{M}(\nabla)$.
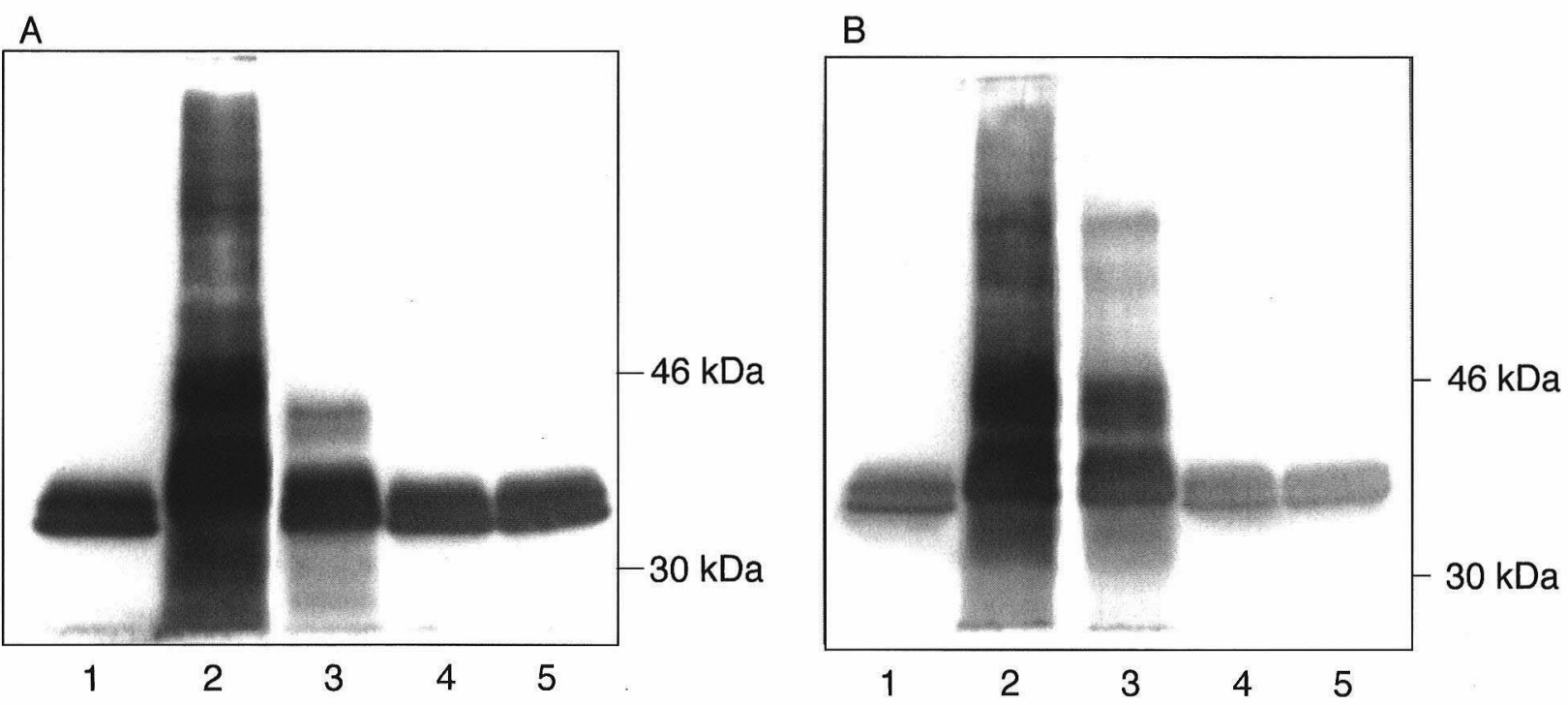

Fig. 2. Effect of AsA on oxidative modification of apoE in VLDL. VLDL was oxidized over a period of $12 \mathrm{~h}$ by AAPH (A) or by SIN-1 (B) as described in Fig. 1. The oxidized VLDL samples were subjected to immunoblot analysis using the anti-apoE antibody. Lane 1, intact VLDL; lane 2, VLDL oxidized in the absence of AsA; lane 3, VLDL oxidized in the presence of $200 \mu \mathrm{M}$ AsA; lane 4, VLDL oxidized in the presence of $500 \mu \mathrm{M}$ AsA; lane 5, VLDL oxidized in the presence of $1,000 \mu \mathrm{M}$ AsA.

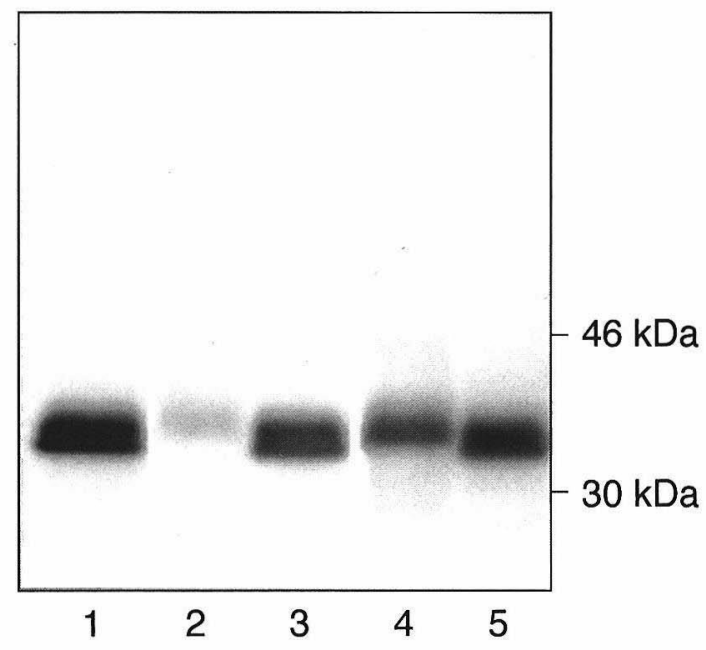

Fig. 3. Heparin-binding activity of apoE in oxidized VLDL. VLDL previously oxidized for $12 \mathrm{~h}$ was incubated with $50 \mathrm{mg}$ of heparin-immobilized Sepharose CL-6B for $3 \mathrm{~h}$ at $4^{\circ} \mathrm{C}$. The heparin-binding fraction was subjected to immunoblot analysis. Lane 1, intact VLDL; lane 2, VLDL oxidized by AAPH in the absence of AsA; lane 3, VLDL oxidized by AAPH in the presence of $1,000 \mu \mathrm{M}$ AsA; lane 4, VLDL oxidized by SIN-1 in the absence of AsA; lane 5, VLDL oxidized by SIN-1 in the presence of $1,000 \mu \mathrm{M}$ AsA. 
arin in glycosaminoglycans are mainly due to the residues of basic amino acids, which contribute to the uptake of VLDL by hepatocytes $(15,16)$. Kato et al. (17) have reported that the lysine residue of apolipoprotein in LDL is reacts easily with lipid hydroperoxides. As shown in Fig. 3, intact apoE in VLDL is responsible for the heparin-binding activity (lane 1). In this connection, the heparin-binding activity of apoE was decreased by AAPH-induced (lane 2) or somewhat SIN-1-induced (lane 4) VLDL oxidation for $12 \mathrm{~h}$. This fact suggests that the lysine residue of apoE might be modified by $\mathrm{CE}-\mathrm{OOH}$ arisen from VLDL oxidation $(18,19)$. It seems likely that the oxidative modification of apoE impairs VLDL metabolism and accumulates oxidized VLDL in the circulatory system. In practice, AsA at 1,000 $\mu \mathrm{M}$ disturbed a lowering of the heparin-binding activity of apoE in VLDL oxidized by AAPH (lane 3) or SIN-1 (lane 5).

Our data suggest that AsA existing in blood serves as a preventive against free radical-induced oxidation of apoE in VLDL.

\section{REFERENCES}

1) Steinbrecher UP, Zhang HF, Lougheed M. 1990. Role of oxidatively modified LDL in atherosclerosis. Free Radic Biol Med 9: 155-168.

2) Berliner JA, Heinecke JW. 1996. The role of oxidized lipoproteins in atherogenesis. Free Radic Biol Med 20: 707-727.

3) Esterbauer H, Schmidt R, Hayn M. 1997. Relationships among oxidation of low-density lipoprotein, antioxidant protection, and atherosclerosis. Adv Pharmacol 38 : $425-456$.

4) Steinberg D. 1997. Low density lipoprotein oxidation and its pathobiological significance. J Biol Chem 272: 20963-20966.

5) Mohr D, Stocker R. 1994. Radical-mediated oxidation of isolated human very-low-density lipoprotein. Arterioscler Thromb 14: 1186-1192.

6) Arai H, Kashiwagi S, Nagasaka Y, Uchida K, Hoshii Y, Nakamura K. 1999. Oxidative modification of apolipoprotein E in human very-low-density lipoprotein and its inhibition by glycosaminoglycans. Arch Biochem Biophys 367: $1-8$.
7) Weisgraber KH. 1994. Apolipoprotein E: structurefunction relationships. Adv Protein Chem 45: 249-302.

8) Mahley RW, Ji ZS. 1999. Remnant lipoprotein metabolism: key pathways involving cell-surface heparan sulfate proteoglycans and apolipoprotein E. J Lipid Res $\mathbf{4 0}$ : $1-16$.

9) Stahl W, Sies H. 1997. Antioxidant defense: vitamins E and $\mathrm{C}$ and carotenoids. Diabetes 46 (Suppl 2): S14-18.

10) Patel RP, Darley-Usmar VM. 1996. Using peroxynitrite as oxidant with low-density lipoprotein. Methods Enzymol 269: 375-384.

11) Hatch FT. 1968. Practical methods for plasma lipoprotein analysis. Adv Lipid Res 6: 1-68.

12) Arai H, Terao J, Abdalla DS, Suzuki T, Takama K. 1996. Coulometric detection in high-performance liquid chromatographic analysis of cholesteryl ester hydroperoxides. Free Radic Biol Med 20: 365-371.

13) Laemmli UK. 1970. Cleavage of structural proteins during the assembly of the head of bacteriophage T4. Nature 227: 680-685.

14) Nomura S, Kashiwagi S, Ito H, Mimura $Y$, Nakamura K. 1993. Degradation of fibrinogen and fibrin by plasmin and nonplasmin proteases in the chronic subdural hematoma: evaluation by sodium dodecyl sulfate-polyacrylamide gel electrophoresis and immunoblot. Electrophoresis 14: 1318-1321.

15) Mahley RW. 1988. Apolipoprotein E: cholesterol transport protein with expanding role in cell biology. Science 240: $622-630$.

16) Cardin AD, Demeter DA, Weintraub HJ, Jackson RL. 1991. Molecular design and modeling of protein-heparin interactions. Methods Enzymol 203: 556-583.

17) Kato Y, Mori Y, Makino Y, Morimitsu Y, Hiroi S, Ishikawa T, Osawa T. 1999. Formation of Nepsilon- (hexanonyl)lysine in protein exposed to lipid hydroperoxide. A plausible marker for lipid hydroperoxide-derived protein modification. J Biol Chem 274: 20406-20414.

18) Hara S, Tanaka T, Yamada M, Nagasaka Y, Nakamura K. 1997. Oxidative modification of apolipoprotein $\mathrm{E}$ and its biological significance. In: Oxygen Homeostasis and Its Dynamics (Ishimura Y, ed), p 631-636. Springer Verlag, Tokyo.

19) Haudin RI, Cohen HJ. 1976. Purification and binding properties of human platelet factor four. J Biol Chem 251: 4273-4282. 